\title{
Identification of a Highly Mobilizable Subset of Human Neutrophil Intracellular Vesicles That Contains Tetranectin and Latent Alkaline Phosphatase
}

Niels Borregaard, Lise Christensen, ${ }^{\star}$ Ole W. Bjerrum, Henrik S. Birgens, ${ }^{\ddagger}$ and Inge Clemmensen

Department of Internal Medicine and Hematology A, and ${ }^{*}$ Department of Pathology, Rigshospitalet; ${ }^{\ddagger}$ Department of Medicine and

Hematology C, Gentofte Hospital; and ${ }^{\S}$ Dakopatts and Department of Clinical Microbiology,

Statens Serum Institute at Rigshospitalet, Copenhagen, Denmark

\begin{abstract}
Tetranectin, a protein recently identified in a wide variety of human secretory cells (Christensen, L., and I. Clemmensen. 1989. Histochemistry. 92:29-35) was found to colocalize with latent alkaline phosphatase activity in fractions well separated from azurophil granules, specific granules, gelatinase-containing granules, and plasma membranes when postnuclear supernatants of nitrogen-cavitated neutrophils were fractionated on discontinuous Percoll density gradients.

Stimulation of intact neutrophils with nanomolar concentrations of FMLP, leukotriene $B_{4}, 10-100 \mathrm{U} / \mathrm{ml}$ of tumor necrosis factor, and granulocyte-macrophage colony-stimulating factor resulted in parallel release of tetranectin and translocation of alkaline phosphatase to the plasma membrane. Furthermore, intracellular pools of tetranectin and latent alkaline phosphatase were completely released from neutrophils under conditions that barely induced release of specific granules containing $\mathrm{B}_{12}$-binding protein. These findings indicate that tetranectin and latent alkaline phosphatase define an easily mobilizable population of cytoplasmic storage organelles in human neutrophils which are functionally distinguishable from azurophil, specific, and gelatinase-containing granules. These organelles may play an important role as stores of membrane proteins that are mobilized to the cell surface during stimulation by inflammatory mediators. (J. Clin. Invest. 1990. 85:408-416.) exocytosis $\bullet$ gelatinase $\bullet$ intracellular membranes - subcellular fractionation
\end{abstract}

\section{Introduction}

Neutrophils play a key role in defense against microorganisms and participate in the pathogenesis of inflammatory diseases $(1,2)$. Essential to execution of these activities is the ability of the neutrophil to respond to various inflammatory mediators by turning on a respiratory burst $(3,4)$ and mobilizing intracellular proteins to the cell surface, some of which are important for adhesion and phagocytosis.

The concept of translocation during activation applies to the $b$-cytochrome and flavin adenine dinucleotide-flavoprotein components of the microbicidal NADPH oxidase $(5,6)$,

Address correspondence to Dr. Niels Borregaard, Department of Medicine and Hematology A, University Hospital (Rigshospitalet), Blegdamsvej 9, DK-2100 Copenhagen, Denmark.

Received for publication 30 December 1988 and in revised form 3 October 1989.

J. Clin. Invest.

(c) The American Society for Clinical Investigation, Inc.

0021-9738/90/02/0408/09 \$2.00

Volume 85, February 1990, 408-416 the glycoprotein Mac-1 functioning as the complement receptor $(C R 3)^{1}$ of importance for adhesion and phagocytosis $(7,8)$, laminin receptors (9), FMLP receptors $(10,11)$, and plasminogen activator (12). Previous subcellular fractionation studies have allocated residence of these functional proteins to the membrane of specific granules or gelatinase-containing granules $(5-13)$, both recognized as secretory granules of neutrophils $(14,15)$. A recent study using immunogold labeling, however, has demonstrated that gelatinase is localized in specific granules (16). Several observations indicate, on the other hand, that an intracellular membrane-bound compartment distinct from the hitherto identified mobilizable granules must exist in human neutrophils to account for the rapid upregulation of both CR1 and CR3 $(17,18)$ and complement decay accelerating factor (19), which takes place in response to stimulation by such stimuli as FMLP, leukotriene $\mathrm{B}_{\mathbf{4}}\left(\mathrm{LTB}_{4}\right)$, and tumor necrosis factor (TNF), which induce only minimal exocytosis of specific granules.

We recently demonstrated (20) that latent alkaline phosphatase activity, that is, the alkaline phosphatase activity that is measured enzymatically only in the presence of detergent, is localized in a compartment that is distinct from the plasma membrane, and from azurophil and specific granules, including gelatinase-containing granules. This compartment is readily mobilized to the plasma membrane in response to stimulation by nanomolar concentrations of FMLP.

Here we show that tetranectin, a protein initially purified from plasma (21), colocalizes with latent alkaline phosphatase on Percoll density gradients. Tetranectin is released from the cells in parallel with translocation of alkaline phosphatase to the plasma membrane in response to stimulation by a variety of inflammatory mediators. Since tetranectin is found in a wide variety of secretory human cells $(22,23)$, this secretory compartment identified in neutrophils by latent alkaline phosphatase and tetranectin may be essential for exocytosis in general.

\section{Methods}

Isolation of cells. Neutrophils were isolated from freshly drawn blood after dextran T-500 (Pharmacia, Uppsala, Sweden) induced sedimentation of erythrocytes and density gradient centrifugation of the leukocyte-rich supernatant on Lymphoprep (Nyegaard Co., Oslo, Norway), and hypotonic lysis of contaminating red cells (5). The isolated neutrophils were resuspended in KRP buffer $(130 \mathrm{mM} \mathrm{NaCl}, 5 \mathrm{mM} \mathrm{KCl}$, $1.27 \mathrm{mM} \mathrm{MgSO}_{4}, 0.95 \mathrm{mM} \mathrm{CaCl}_{2}, 5 \mathrm{mM}$ glucose, $10 \mathrm{mM}$ phosphate, pH 7.4) at $3 \times 10^{7}$ cells $/ \mathrm{ml}$.

Subcellular fractionation. Isolated neutrophils were incubated at $4^{\circ} \mathrm{C}$ for $10 \mathrm{~min}$ in $10 \mathrm{ml} \mathrm{KRP}$ buffer containing $50 \mu \mathrm{l}$ of $\left[{ }^{3} \mathrm{H}\right] \mathrm{Con} \mathrm{A}(60$

1. Abbreviations used in this paper: CR, complement receptor; PI-PLC, phosphatidylinositol-specific phospholipase C; TBS, Tris-buffered saline; TNF, tumor necrosis factor. 
$\mathrm{Ci} / \mathrm{mmol}, 25 \mu \mathrm{Ci} / \mathrm{ml}$; Amersham Corp., Arlington Heights, IL). The cells were then sedimented by centrifugation and resuspended in $5 \mathrm{ml}$ KRP buffer containing $5 \mathrm{mM}$ diisopropyl fluorophosphate (Sigma Chemical Co., St. Louis, MO) and kept on ice for $10 \mathrm{~min}$. After an additional centrifugation the cells were resuspended in $13 \mathrm{ml}$ disruption buffer $(100 \mathrm{mM} \mathrm{KCl}, 3 \mathrm{mM} \mathrm{NaCl}, 1 \mathrm{mM}$ ATPNa $2,3.5 \mathrm{mM}$ $\mathrm{MgCl}_{2}, 10 \mathrm{mM}$ Pipes, pH 7.2) containing $0.5 \mathrm{mM}$ PMSF, and disrupted by nitrogen cavitation as described (5). Nuclei and intact cells were sedimented by centrifugation $400 \mathrm{~g}$ for $15 \mathrm{~min}\left(\mathrm{P}_{1}\right)$ and 10 $\mathrm{ml}$ of the postnuclear supernatant $\left(\mathrm{S}_{1}\right)$ was applied on top of a 28-ml two-layer Percoll density gradient $(1.05 / 1.12 \mathrm{~g}$ per $\mathrm{ml})$ containing 0.5 mM PMSF as described (5). All procedures after Dextran sedimentation were carried out in the cold. After centrifugation of the density gradient $1.5-\mathrm{ml}$ fractions were collected from the bottom and assayed.

Partial purification of tetranectin. The top band ( $\gamma$-band) of a gradient from $10^{9}$ unstimulated neutrophils was aspirated by hand, including the material between the intermediate band, the $\beta$-band, and the $\gamma$-band. Percoll was removed by centrifugation (5) and the biological material was resuspended in $2.5 \mathrm{ml}$ PBS containing $0.7 \%$ Triton $\mathrm{X}-114$. Triton phase separation was carried out (24), and $2 \mathrm{ml}$ of the supernatant was dialyzed against $0.05 \mathrm{M}$ Tris- $\mathrm{HCl}, \mathrm{pH} \mathrm{8.0,} \mathrm{overnight}$ and applied on a 1-ml Mono Q column (Pharmacia-LKB) equilibrated in dialysis buffer for FPLC. The column was washed in five bed-volumes of buffer and eluted by a linear gradient of $\mathrm{NaCl}$ from 0 to $0.5 \mathrm{M}$ in buffer. $0.5-\mathrm{ml}$ fractions were collected and assayed for tetranectin by ELISA. The fractions that contained peak amounts of tetranectin were assayed by Western blot using affinity-purified antitetranectin antibody.

Assays. $50 \mu \mathrm{l}$ was taken for liquid scintillation counting to quantitate $\left[{ }^{3} \mathrm{H}\right]$ Con A. $200 \mu$ l was taken for ELISA quantitation of tetranectin as described below. $B_{12}$-binding protein (25), alkaline phosphatase (26), and $\beta$-glucuronidase (27) were assayed as described with modification as given in reference 5 . Gelatinase was assayed as described (15) with ${ }^{3} \mathrm{H}$-acetylated (Amersham Corp.) gelatin as substrate. The gelatin was prepared from type III collagen from calf skin (Sigma Chemical Co.). Myeloperoxidase was assayed using $o$-dianisidine as substrate (1972. Worthington Enzyme Manual. Worthington Biochemical Corp., Freehold, NJ. 43) or by spectral analysis using an absorption coefficient of the 472 -nm peak of $75 \cdot \mathrm{mM}^{-1} \cdot \mathrm{cm}^{-1}(28)$. Lactate dehydrogenase was assayed using a commercial kit (Sigma Chemical Co.). 1 $\mathrm{U}$ of enzyme activity is the amount that converts $1 \mu \mathrm{mol}$ or $1 \mu \mathrm{g}$ substrate per min at assay temperature.

Antibodies. Rabbit Ig against human tetranectin (code A 371, IgG concentration $2.5 \mathrm{~g} /$ liter, Dakopatts, Ltd., Glostrup, Denmark) was purified by binding to a tetranectin affinity column $(6 \mathrm{mg}$ tetranectin coupled to $5 \mathrm{ml}$ Sepharose 4B [Pharmacia]). Bound antibody was eluted by $4 \mathrm{M} \mathrm{KSCN}$ and dialyzed against $0.1 \mathrm{M}$ sodium carbonate, $\mathrm{pH}$ 8.0. Biotinylation was then performed by adding $0.4 \mathrm{mg}$ biotinamidocaproate $N$-hydroxysuccimide (Sigma Chemical Co.) dissolved in $8 \mu$ l dimethylformamide to $3.75 \mathrm{ml}(0.4 \mathrm{~g} /$ liter $)$ of the affinity-purified antibody. After incubation for $2 \mathrm{~h}$ at room temperature the conjugated antibody was dialyzed against PBS. This antibody was used in the ELISA for detection of tetranectin. For use in Western blotting, affinity purification of the commercial antibody was performed by elution from nitrocellulose paper. Briefly, $40 \mu \mathrm{g}$ of purified tetranectin was run in $10 \%$ SDS-PAGE. One lane of the slab gel was cut off and stained with Coomassie blue. The rest was transferred to $0.1-\mu \mathrm{m}$ nitrocellulose paper (Schleicher \& Schuell, Inc., Dassel, FRG) and incubated for $1 \mathrm{~h}$ at room temperature in $50 \mathrm{ml}, 50 \mathrm{mg} /$ liter rabbit antitetranectin IgG. The strip corresponding to the position of tetranectin was cut out and incubated in $0.2 \mathrm{M}$ glycine- $\mathrm{HCl}, \mathrm{pH} 2.8$, for $5 \mathrm{~min}$. The paper was removed and the eluent was neutralized with $1 \mathrm{M}$ Tris-base. The concentration of the eluted antibody was $100 \mathrm{mg} / \mathrm{liter}$ as estimated by the absorbance at $280 \mathrm{~nm}$. The antibody was used undiluted as primary antibody in Western blotting after addition of Tween-20 to a final concentration of $0.6 \%$.

ELISA procedure. Tetranectin was determined in an ELISA as recently described (29) but with biotinylated affinity-purified antibody diluted 1:1,000 in place of horseradish peroxidase-conjugated antitetranectin and with horseradish peroxidase-conjugated avidin diluted 1:5,000 as detecting system (code P 364; Dakopatts). Plates were read at $492 \mathrm{~nm}$ in a 2550 EIA reader (Bio-Rad Laboratories, Richmond, CA). Serial dilutions of purified tetranectin and pooled plasma were used as standards.

Immunohistochemical staining of cells. Isolated neutrophils in KRP buffer at $10^{7}$ cells $/ \mathrm{ml}$ were sedimented on glass slides covered by $2 \mathrm{mg} / \mathrm{ml} \mathrm{pectin}$ and $80 \mathrm{mg} / \mathrm{ml}$ glycerol in distilled water in a cytospin (Shandon Southern Instruments Inc., Sewickley, PA) cytocentrifuge at $8,000 \mathrm{rpm}$ for $5 \mathrm{~min}$. The cells were then fixed for $30 \mathrm{~min}$ at room temperature with $4 \%$ paraformaldehyde in $0.1 \mathrm{M}$ sodium phosphate buffer, $\mathrm{pH} 7.3$, and washed with PBS. The cells were then permeabilized by incubation with $0.05 \mathrm{M}$ Tris- $\mathrm{HCl}, \mathrm{pH} 7.5,0.15 \mathrm{M} \mathrm{NaCl}$ (TBS) containing 1\% Triton X-100 (TBS-Triton) for $30 \mathrm{~min}$, washed with PBS, and incubated with 5\% BSA (Behringwerke, Marburg, FRG) in TBS for $30 \mathrm{~min}$. Thereafter the cells were incubated at $4^{\circ} \mathrm{C}$ for $24 \mathrm{~h}$, and then at $20^{\circ} \mathrm{C}$ for $24 \mathrm{~h}$ with either rabbit polyclonal antibody against human tetranectin (Dakopatts Ltd., Copenhagen, Denmark) or rabbit polyclonal antibody against human lactoferrin (Dakopatts Ltd. code A 186), both diluted to $25 \mathrm{mg} /$ liter in TBS containing 5\% BSA. After washing with PBS twice for 10 min the slides were incubated for $30 \mathrm{~min}$ at room temperature with alkaline phosphatase-conjugated swine anti-rabbit Ig (Dakopatts Ltd. code D 306) diluted 1:20 in TBS. After washing twice for $10 \mathrm{~min}$ with PBS the cells were developed as follows: $2 \mathrm{mg}$ naphthol AS-MX (Sigma Chemical Co.) was dissolved in $0.2 \mathrm{ml}$ dimethyl formamide and added to $9.8 \mathrm{ml} 0.1 \mathrm{M}$ Tris- $\mathrm{HCl}, \mathrm{pH}$ 8.2. $1 \mathrm{mM}$ levamisol was added to block endogenous alkaline phosphatase activity. Immediately before use Fast Red 4-chloro-O-toluidine diazotate (Sigma Chemical Co.) was added to a final concentration of $1 \mathrm{mg} / \mathrm{ml}$, and this solution was filtered directly on the slides. After incubation at room temperature for $30 \mathrm{~min}$ the slides were washed in running tap water, counterstained in Mayer's hematoxylin, mounted in glycergel (Dakopatts Ltd.), and viewed and photographed under oil.

Materials. Phosphatidylinositol-specific phospholipase C (PI-PLC) purified from culture supernatants of Bacillus thuringiensis was a generous gift from Dr. Martin Low, Cornell University Medical School. rTNF $\alpha$ (Natl. Inst. Biol. Stand. Control, Polters Bar, UK) and rGMCSF (a generous gift from Dr. S. Gillis, Immunex Corp., Seattle, WA) were kindly provided by Dr. Klaus Bendtzen, Dept. of Immunology, Rigshospitalet. Both cytokines were found to contain $<1$ pg endotoxin $/ 10^{4} \mathrm{U}$. FMLP and $\mathrm{LTB}_{4}$ were from Sigma Chemical Co.

\section{Results}

The subcellular localization of azurophil granules (myeloperoxidase), specific granules $\left(\mathrm{B}_{12}\right.$-binding protein), gelatinase, and alkaline phosphatase in the absence or presence of detergent, tetranectin, and plasma membranes $\left(\left[{ }^{3} \mathrm{H}\right]\right.$ Con $\left.A\right)$ is given in Fig. 1. This confirms our earlier finding that latent alkaline phosphatase is localized in a sedimentable compartment with a density slightly higher than that of plasma membranes (20). More important is the demonstration that tetranectin is colocalized with latent alkaline phosphatase. This pattern has been invariably observed in all of $>10$ experiments. A typical experiment is presented. The densities at the localization of peak of markers (Fig. $1 \mathrm{~A}$ ) were as follows: myeloperoxidase, 1.120 $\mathrm{g} / \mathrm{ml} ; \mathrm{B}_{12}$-binding protein, $1.078 \mathrm{~g} / \mathrm{ml}$; tetranectin, $1.025 \mathrm{~g} / \mathrm{ml}$; plasma membranes, $1.015 \mathrm{~g} / \mathrm{ml}$. These are in accordance with previously reported results (5).

Peak gelatinase activity was often located one fraction higher in the gradient than peak $B_{12}$-binding protein. We have observed that detergent-solubilized azurophil granules readily inactivate gelatinase (Bjerrum, O. W., and N. Borregaard, unpublished observations). Such inactivation is likely to take 

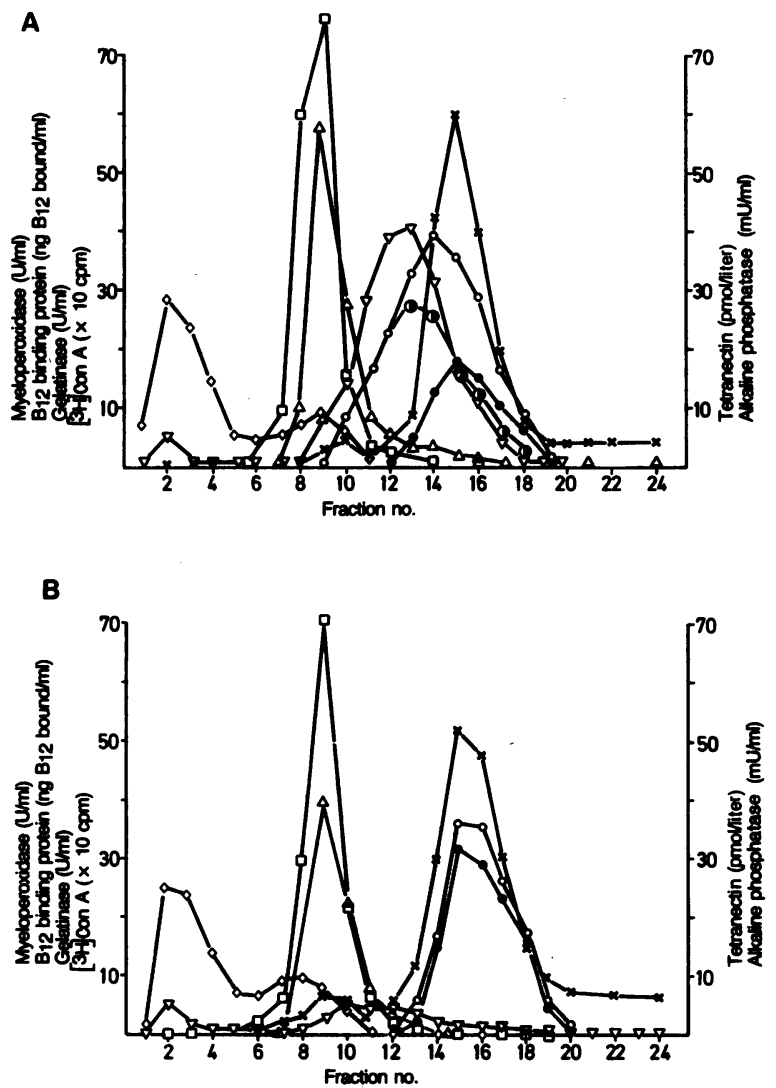

Figure 1. $8.4 \times 10^{8}$ neutrophils were labeled with $\left[{ }^{3} \mathrm{H}\right] \mathrm{Con} \mathrm{A}$ as described, suspended in KRP buffer at $3 \times 10^{7}$ cells $/ \mathrm{ml}$, and divided in two. One sample $(A)$ was kept on ice; the other $(B)$ was incubated at $37^{\circ} \mathrm{C}$ for $15 \mathrm{~min}$ in the presence of $10^{-8} \mathrm{M}$ FMLP. The cells were then disrupted by nitrogen cavitation, and the postnuclear supernatant from each was fractionated on Percoll density gradients. Recoveries of material loaded on the gradient ranged between 80 and $105 \%$. ๑, Alkaline phosphatase in the absence of Triton; 0 , alkaline phosphatase in the presence of $0.2 \%$ Triton X-100; 0 , latent alkaline phosphatase (calculated); $\times,\left[{ }^{3} \mathrm{H}\right]$ Con $A ; \nabla$, tetranectin; $\Delta$, gelatinase; $\square, B_{12}$-binding protein; $\diamond$, myeloperoxidase.

place in the fractions containing specific granules, since these are contaminated with azurophil granules thus explaining the lack of exact colocalization of $B_{12}$-binding protein and gelatinase.

The colocalization of tetranectin and latent alkaline phosphatase was further corroborated by studies on stimulated cells (Fig. 1 B). Stimulation of intact cells with $10^{-8} \mathrm{M}$ FMLP resulted in almost complete disappearance of both latent alkaline phosphatase activity and tetranectin. Tetranectin was recovered in the supernatant of stimulated cells (see below), whereas alkaline phosphatase was translocated to the plasma membrane. Tetranectin was assayed immunologically with an affinity-purified polyclonal antibody. To demonstrate the presence of tetranectin in neutrophils, tetranectin was partially purified from the $\gamma$-band from unstimulated neutrophils (see

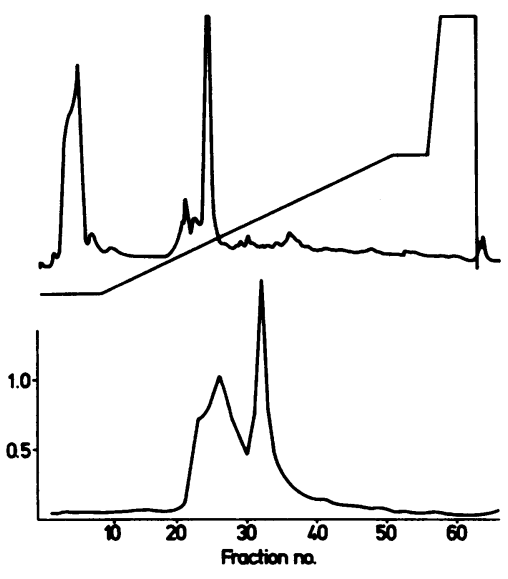

Figure 2. FPLC profile of 280-nm absorbance (top) and 492-nm

ELISA reading of tetranectin (bottom) of Triton X-114-treated $\gamma$ band from unstimulated neutrophils. The profile of the linear salt gradient from 0 to 0.5 $\mathrm{M} \mathrm{NaCl}$ followed by 2 $\mathrm{M} \mathrm{NaCl}$ is given in the upper part of the figure.

Methods) by FPLC chromatography (Fig. 2). Two main protein peaks were eluted from the Mono $Q$ column. The first peak represented proteins that did not bind to the column. The second protein peak eluted at $0.2 \mathrm{M} \mathrm{NaCl}$. None of these peaks contained tetranectin as estimated by ELISA. Tetranectin was eluted in two peaks at 0.21 and $0.28 \mathrm{M} \mathrm{NaCl}$. Western blot (Fig. 3) demonstrated that in addition to the $17-\mathrm{kD}$ tetranectin band normally observed by SDS-PAGE on plasma (21), neutrophils contained an $82-\mathrm{kD}$ tetranectin band. The 17- and 82-kD tetranectin bands were observed in both tetranectin peaks eluted from the FPLC column. Only the Western blot of the second tetranectin peak is shown. Elution experiments confirmed immunological cross-reactivity between the high and low molecular weight tetranectin bands. Similar high molecular weight tetranectin immunoreactivity was found in other tissues (kidney, ventricular mucosa, and fibroblasts in culture [23]). The nature and function of this high molecular form of tetranectin is unknown.

These studies were corroborated by immunohistochemical staining of fixed, permeabilized cells that were either unperturbed or had been stimulated by $10^{-8} \mathrm{M}$ FMLP before fixation. Fig. 4 shows a granular labeling of tetranectin. This granular labeling was almost completely lost after stimulation by FMLP in contrast to the labeling of lactoferrin, a marker for specific granules, which was unchanged by stimulation.

These studies indicate that tetranectin is localized in the matrix of a readily mobilized vesicular structure, and that alkaline phosphatase is localized on the intravesicular surface of the membrane and becomes translocated to the outer surface

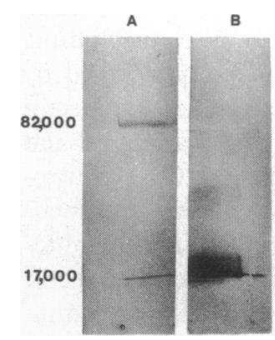

Figure 3. Immunoblot with affinity-purified antitetranectin. Lane $A$, partially purified tetranectin from human neutrophils $(1 \mu \mathrm{g}$ protein from eluted peak [fraction no. 34] from Mono $Q$ column in Fig. 2). Lane $B$, purified human plasma tetranectin ( $5 \mu \mathrm{g}$ protein).

Figure 4. Isolated neutrophils $\left(3 \times 10^{7} / \mathrm{ml}\right.$ in KRP buffer) were either incubated at $37^{\circ} \mathrm{C}$ with $10^{-8} \mathrm{M}$ FMLP or kept on ice (control). After 15 min, 2 vol of ice-cold KRP buffer was added to both and the cells were sedimented onto glass slides by cytocentrifugation and processed for immunohistochemistry. $A$, Control cells stained for tetranectin; $B$, FMLP-stimulated cells stained for tetranectin; $C$, control cells stained for lactoferrin; $D$, FMLP-stimulated cells stained for lactoferrin. The slides were viewed under immersion oil with 100 -fold magnification and photographed. Staining: immune-alkaline phosphatase counterstained with Mayer's hematoxylin. 

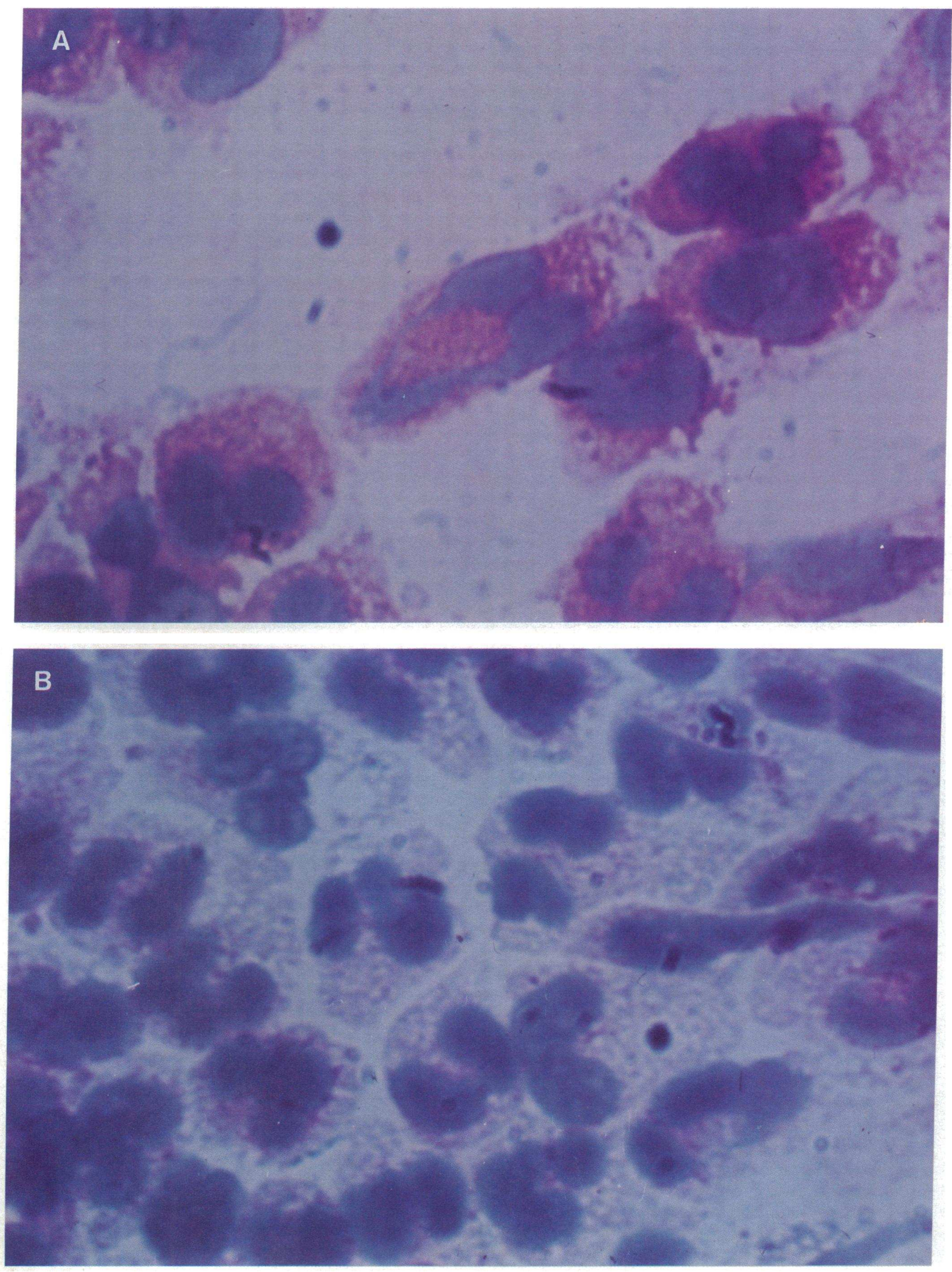

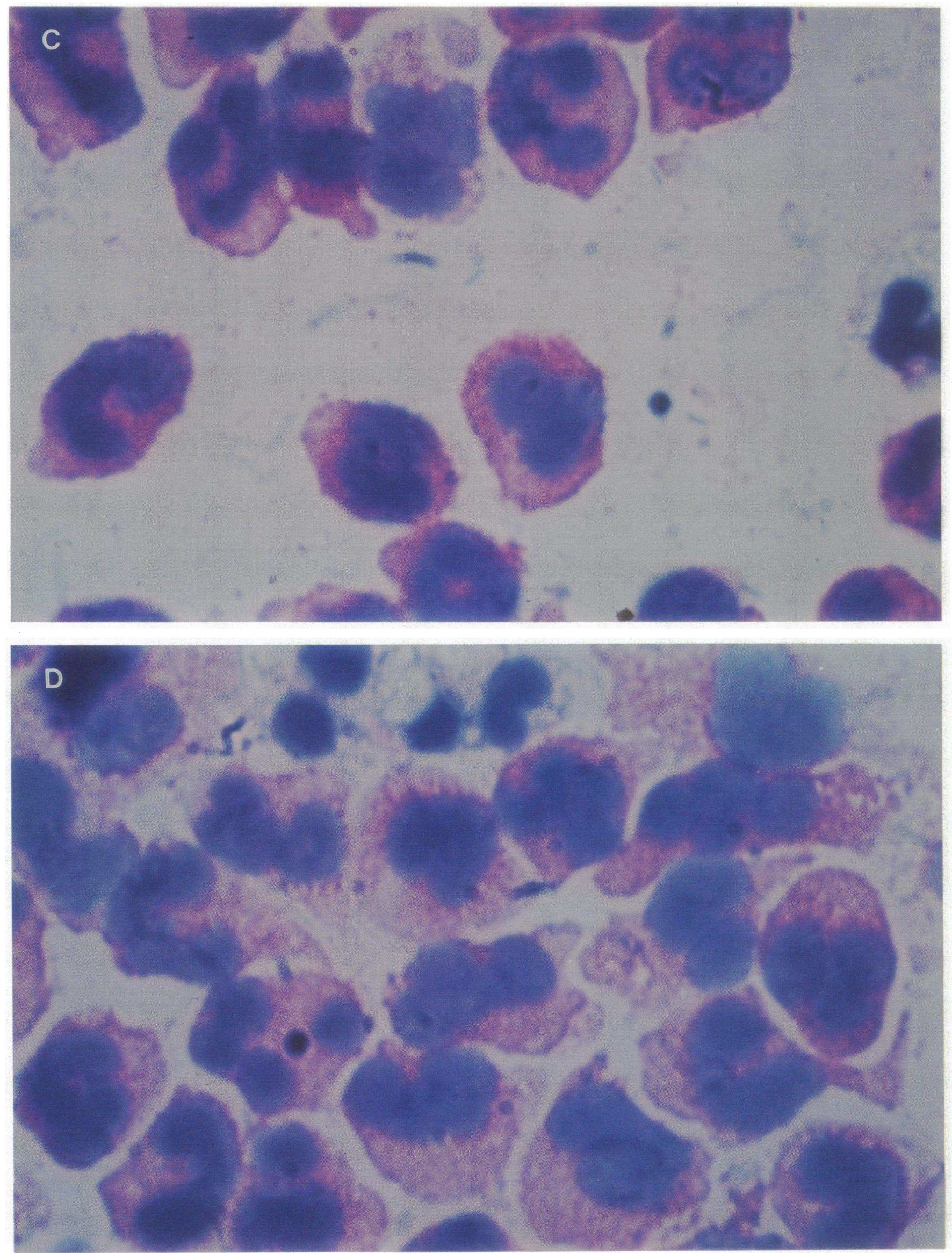
of the plasma membrane when these vesicles fuse with the plasma membrane and tetranectin is exocytosed. Such a hypothesis explains the latency of alkaline phosphatase in both intact unstimulated cells and subcellular fraction from these, and also explains the disappearance of latency and the shift in subcellular localization of alkaline phosphatase activity after stimulation.

This hypothesis was further validated by studies using PIPLC. Alkaline phosphatase (30), like some other membranebound proteins (e.g., Fc receptor type III [31], 5'-nucleotidase, and decay accelerating factor [32]), is known to be anchored to membranes via a covalent protein-phosphatidyl-inositol-glycan bond. This anchoring may be split by PI-PLC. If our hypothesis is correct, then latent alkaline phosphatase activity should not be susceptible to PI-PLC, whereas alkaline phosphatase, which can be measured in the absence of detergent, should be susceptible. This was confirmed by the two experiments reported in Table I. It is readily observed that PI-PLC can release the majority of alkaline phosphatase of $\gamma$-band from FMLP-stimulated cells, i.e., cells where all alkaline phosphatase can be measured in the absence of detergent (70 and $75 \%$ of total alkaline phosphatase from the $\gamma$-band is released after PI-PLC treatment in experiments A and B, respectively). Only 27 and $30 \%$ of total alkaline phosphatase is liberated by PI-PLC from the $\gamma$-band of unstimulated cells (experiments A and B). However, some of the alkaline phosphatase in the $\gamma$-band from unstimulated cells is latent, i.e., can only be measured in the presence of detergent. To estimate the susceptibility of latent phosphatase to PI-PLC, one has to compare the amount of latent alkaline phosphatase present in the pellet before and after incubation with PI-PLC. These calculated figures are: experiment A, $43.1-21.9=21.2$ before PI-PLC vs. $41.3-17.7=23.6$ after PI-PLC; experiment B, $145-83$ $=62$ before PI-PLC vs. $137-48.9=88$ after PI-PLC. Thus it is demonstrated that latent alkaline phosphatase activity is present only in $\gamma$-bands from unstimulated cells, and that this latent alkaline phosphatase is protected from the action of PI-PLC.

To rule out that the differences in susceptibility of alkaline phosphatase to PI-PLC are due to differences in sidedness of plasma membrane vesicles induced by FMLP stimulation, the susceptibility to PI-PLC of alkaline phosphatase from intact neutrophils was investigated. When unstimulated neutrophils in KRP buffer at $3 \times 10^{7}$ cells $/ \mathrm{ml}$ were incubated with $5 \mathrm{U} / \mathrm{ml}$ PI-PLC for $15 \mathrm{~min}$ at $37^{\circ} \mathrm{C}$ and then sedimented by centrifugation, 32 and $36 \%$ of total cell alkaline phosphatase was liberated to the supernatant in two experiments. If the cells had been stimulated with $10^{-8} \mathrm{M}$ FMLP for $15 \mathrm{~min}$ at $37^{\circ} \mathrm{C}$ before incubation with PI-PLC, 57 and $63 \%$ of total alkaline phosphatase was liberated. No release of alkaline phosphatase was observed in the absence of PI-PLC, and $<3 \%$ lactate dehydrogenase was liberated.

The subcellular fractionation studies indicate that the intracellular compartment(s) identified by latent alkaline phosphatase and tetranectin are mobilized in response to nanomolar concentrations of FMLP. To examine both whether tetranectin release and translocation of alkaline phosphatase always occurred in parallel, and the sensitivity of exocytosis of

Table I. Release of Alkaline Phosphatase from Plasma Membrane and Secretory Granules by PI-PLC

\begin{tabular}{|c|c|c|c|c|c|c|}
\hline \multirow[b]{3}{*}{ Sample } & \multicolumn{3}{|c|}{ Control } & \multicolumn{3}{|c|}{ FMLP } \\
\hline & \multirow[b]{2}{*}[{}^{3}\mathrm{H}]{$\operatorname{Con} \mathrm{A}$} & \multicolumn{2}{|c|}{ Alkaline phosphatase } & \multirow[b]{2}{*}[{}^{3}\mathrm{H}]{$\operatorname{Con} \mathrm{A}$} & \multicolumn{2}{|c|}{ Alkaline phosphatase } \\
\hline & & -Triton & +Triton & & -Triton & +Triton \\
\hline & $c p m$ & & & $c p m$ & & \\
\hline \multicolumn{7}{|l|}{$4^{\circ} \mathrm{C}$} \\
\hline Supernatant A & 288 & 6.3 & 10.3 & 216 & 13.0 & 13.7 \\
\hline Pellet A & 1,760 & 24.3 & 43.8 & 1,169 & 59.8 & 61.6 \\
\hline Supernatant B & 263 & 10.9 & 19.0 & 184 & 15.7 & 18.3 \\
\hline Pellet B & 1,500 & 49.2 & 139 & 1,856 & 164 & 176 \\
\hline \multicolumn{7}{|l|}{$37^{\circ} \mathrm{C}$} \\
\hline Supernatant A & 514 & 9.3 & 14.2 & 369 & 17.0 & 20.0 \\
\hline Pellet A & 832 & 21.9 & 43.1 & 946 & 53.0 & 53.5 \\
\hline Supernatant B & 593 & 13.4 & 20.3 & 550 & 44.0 & 41.2 \\
\hline Pellet B & 1,211 & 83.0 & 145 & 2,400 & 144 & 161 \\
\hline \multicolumn{7}{|c|}{$37^{\circ} \mathrm{C}+$ PI-PLC (1 U/ml) } \\
\hline Supernatant A & 464 & 15.0 & 17.4 & 406 & 62.0 & 64.3 \\
\hline Pellet A & 786 & 17.7 & 41.3 & 899 & 18.1 & 20.9 \\
\hline Supernatant B & 659 & 46.9 & 51.3 & 564 & 165 & 164 \\
\hline Pellet B & 1,848 & 48.9 & 137 & 1,633 & 66.4 & 68.9 \\
\hline
\end{tabular}

Human neutrophils were isolated $\left(6.2 \times 10^{8}\right.$ in experiment $\mathrm{A} ; 9.0 \times 10^{8}$ in experiment $\left.\mathrm{B}\right)$, labeled with [ $\left.{ }^{3} \mathrm{H}\right] \mathrm{Con} \mathrm{A}$, and divided into two samples. One was incubated at $37^{\circ} \mathrm{C}$ for $15 \mathrm{~min}$ with $10^{-8} \mathrm{M} \mathrm{FMLP}$ at a concentration of $3 \times 10^{7} \mathrm{cells} / \mathrm{ml}$; the other was kept at $4^{\circ} \mathrm{C}$ as control. Subcellular fractionation was then performed as described. The $\gamma$-bands were aspirated and Percoll was removed by centrifugation, and the material from the $\gamma$-band was diluted to $5 \mathrm{ml}$ in KRP buffer. $600-\mu 1$ samples were incubated for $1 \mathrm{~h}$ at $37^{\circ} \mathrm{C}$ in the presence and absence of PIPLC $(1 \mathrm{U} / \mathrm{ml})$ and centrifuged at $20,000 \mathrm{~g}$ for $20 \mathrm{~min}$. The supernatant was aspirated and the pellet was resuspended to $600 \mu \mathrm{l}$ in KRP buffer. Alkaline phosphatase was measured in the presence and absence of $0.2 \%$ Triton $\mathrm{X}-100$. 
this compartment to inflammatory mediators, the release of tetranectin from intact cells and the dependence on detergent of alkaline phosphatase activity was examined in response to varying concentrations of FMLP, $\mathrm{LTB}_{4}, \mathrm{TNF} \alpha$, and granulocyte-macrophage colony-stimulating factor (GM-CSF) (Fig. 5, $A-D$ ). It is observed that tetranectin release and the rise in detergent-independent alkaline phosphatase activity occur in parallel, and that maximal release of tetranectin and complete upregulation of detergent-independent alkaline phosphatase activity occur under conditions when only minimal release of the secretory granule marker vitamin $\mathrm{B}_{12}$-binding protein takes place. Secreted $B_{12}$-binding protein was not inactivated (33) since no difference in total $B_{12}$-binding capacity was observed between control cells and activated cells (data not shown).

It should be noted that not all tetranectin could be released from the cells even when alkaline phosphatase was fully detergent independent. Subcellular fractionation of both stimulated and unstimulated cells disclosed that this tetranectin activity was sedimented with the nuclei after cavitation. The amount of nuclei-associated tetranectin was the same in stimulated and unstimulated cells, and accounted for $35.7 \pm 3.5 \%(n=5)$ of total cell tetranectin in unstimulated cells.

\section{Discussion}

The existence of two distinct mobilizable types of granules, the azurophil and the specific granules, has been recognized since the pioneer work of Bainton et al. (34) and supported by subcellular fractionation studies $(35,36)$. More recently, Dewald et al. (15) identified gelatinase as a marker for a novel granule subset with density identical to that of the specific granules, but characterized by a much more extensive exocytosis upon stimulation of the neutrophil. Some proteins are claimed to be associated with the membrane of these gelatinase-containing granules (cytochrome $b_{-245}$ [37], Mac-1 [13], laminin receptors [9]), but a recent study using immunogold labeling has strongly indicated that gelatinase and lactoferrin, a well-established marker for specific granules, are localized in the same granules (16). Our studies on release and subcellular localization of gelatinase and of the specific granule marker, $B_{12}$-binding protein, support this.
Several observations on the incorporation of proteins into the plasma membrane of intact neutrophils indicate the existence of an intracellular pool of membrane that can be incorporated into the plasma membrane in response to stimulation which causes little or no degranulation of specific granules (17-19). The vesicles identified by alkaline phosphatase and tetranectin constitute a likely candidate for the structural basis for this mobilizable membrane store.

Exact colocalization of tetranectin and alkaline phosphatase can only be documented by demonstration of double labeling of the same structures on ultrathin sections of fixed cells with monospecific antibodies to both antigens. These are not yet available. The distribution of tetranectin and latent alkaline phosphatase on density gradients of postnuclear supernatants is consistent with colocalization of the two proteins. Other structures, such as small peroxidase-containing granules $(38)$, calciosomes $(39,40)$, and light $\operatorname{Golgi}(38,39)$ are reported to be localized at the same density as tetranectin and latent alkaline phosphatase on Percoll density gradients. However, those organelles are not exocytosed in response to stimulation. The parallel release of tetranectin and disappearance of latency of alkaline phosphatase observed in intact cells, the disappearance of tetranectin from the postnuclear supernatant and translocation of alkaline phosphatase, and the loss of tetranectin immunoreactivity of intact cells after stimulation show that tetranectin and latent alkaline phosphatase are either localized in the same mobilizable structures or in different structures with identical densities and identical sensitivity to exocytosis by a variety of stimuli.

The finding of both high ( $82 \mathrm{kD}$ ) and low molecular weight $(17 \mathrm{kD})$ tetranectin in the $\gamma$-band of unstimulated neutrophils, as opposed to only low molecular weight tetranectin in plasma, indicates that the tetranectin in neutrophils has not been taken up from plasma by an endocytotic process since only low molecular weight tetranectin is found in plasma. It is possible that tetranectin is synthesized as the high molecular weight form, and degraded during packing in granules and after secretion. Biosynthesis studies are in progress to address this question.

The ability of PI-PLC to liberate substantial amounts of alkaline phosphatase from stimulated intact cells and from plasma membrane vesicles from stimulated cells but not unstimulated cells or from subcellular fractions (the $\boldsymbol{\gamma}$-band from
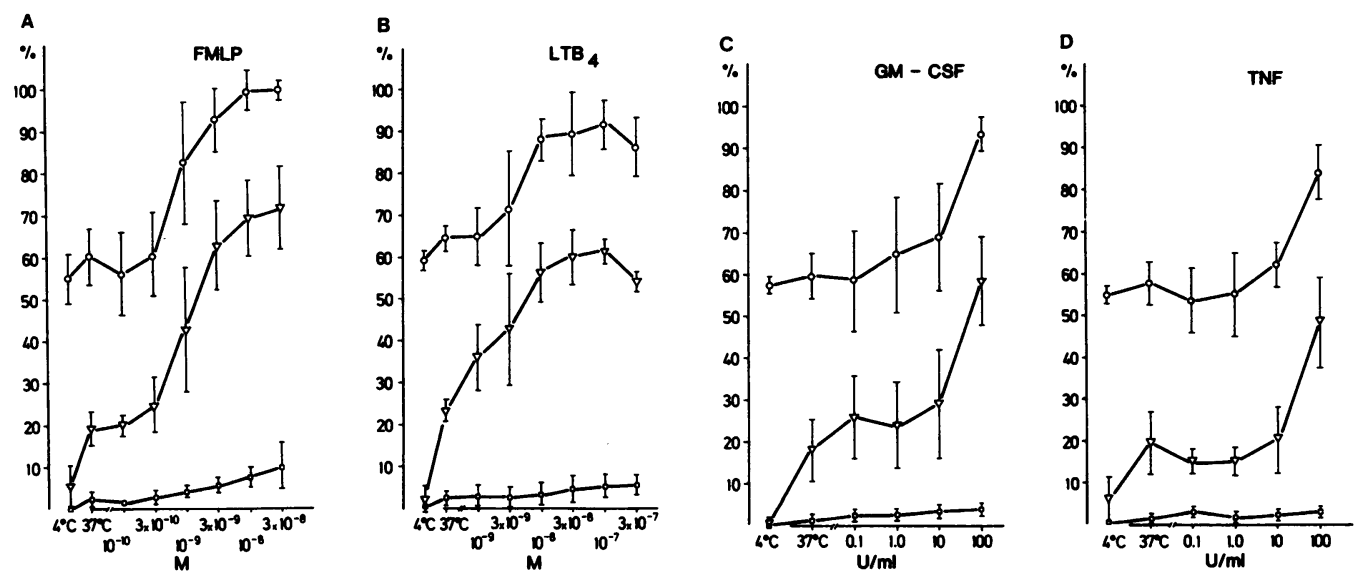

Figure 5. Isolated neutrophils $\left(3 \times 10^{7}\right.$ cells $\left./ \mathrm{ml}\right)$ were incubated either on ice, at $37^{\circ} \mathrm{C}$ with no additions, or at $37^{\circ} \mathrm{C}$ in the presence of various concentrations of FMLP $(A), \mathrm{LTB}_{4}(B)$, GM-CSF $(C)$, or TNF $(D)$. After 20-min incubation the cells were sedimented by centrifugation and resuspended in equal volumes of ice-cold buffer. Assays were performed as described. Results are mean and SD of three independent experiments. Alkaline phosphatase was measured on

cells in the absence and presence of $0.2 \%$ Triton $\mathrm{X}-100$. Other assays were carried out in the presence of $0.2 \%$ Triton X-100. $0, \%$ ratio of activity of alkaline phosphatase in the absence or presence of Triton X-100; $\square, \%$ release of $B_{12}$-binding protein; $\nabla, \%$ release of tetranectin. 
unstimulated cells) containing latent alkaline phosphatase activity, strongly indicates that latent alkaline phosphatase is alkaline phosphatase that is localized on the intragranular site of the granule membrane, and that this alkaline phosphatase becomes translocated to the outer surface of the plasma membrane during exocytosis as nonlatent alkaline phosphatase. This supports the concept that intracellular membrane vesicles may provide a store for proteins that will become expressed on the surface of the plasma membrane during activation of the cell.

The kinetics of upregulation of alkaline phosphatase in the plasma membrane and the parallel release of tetranectin in response to FMLP, $\mathrm{LTB}_{4}$, TNF, and GM-CSF show that these vesicles are mobilized under conditions that may occur during diapedesis and chemotaxis. The exocytosis of these vesicles may be important by providing the plasma membrane with receptors that are active during chemotaxis and may prepare the cell for subsequent phagocytic events.

Although alkaline phosphatase has been demonstrated before in intracellular vesicles, termed phosphasomes (41), the mobilization and therefore the potential functional significance of these was overlooked. Since these mobilizable vesicles are exocytosed more extensively and more readily than other granules of the neutrophil, we propose that they should be named secretory vesicles of the neutrophil. The fact that tetranectin, as found in these vesicles, is also identified in cytoplasmic organelles in a wide variety of other human secretory cells $(22,23)$ suggests that these vesicles may have universal importance for the secretory process, and may represent a general principle in cell biology, in addition to serving specific functions in the neutrophil.

\section{Acknowledgments}

The expert technical assistance of Mrs. Charlotte Horn, Mrs. Anne Christensen, and Mrs. Anna Lise Ryberg is gratefully acknowledged.

This work was supported by the Danish Medical Research Council (grants 12-6234 and 12-7790), the Danish Arthritis Foundation, the Danish Cancer Society (grants 86-132, 87-126, and 87-127), Anders Hasselbalch's Fund, Amalie Jørgensens Mindelegat, Brøchner-Mortensen's Fund, P. Carl Petersen's Fund, Lundbeck Fonden, Nordisk Insulin Fund, the National Association Against Lung Diseases, and the Danish Hospital Foundation for Medical Research, Region of Copenhagen, the Faroe Islands, and Greenland.

\section{References}

1. Henson, P. M., and R. B. Johnston, Jr. 1987. Tissue injury in inflammation. Oxidants, proteinases, and cationic proteins. J. Clin. Invest. 79:669-674.

2. Malech, H. L., and J. I. Gallin. 1987. Current concepts in immunology: neutrophils in human diseases. N. Engl. J. Med. 317:687-694.

3. Holmes, B., R. A. Page, and A. R. Good. 1967. Studies on the metabolic activity of leukocytes from patients with a genetic abnormality of phagocyte function. J. Clin. Invest. 46:1422-1432.

4. Borregaard, N. 1988. The respiratory burst: an overview. In The Respiratory Burst and Its Physiological Significance. A. J. Sbarra and R. A. Strauss, editors. Plenum Publishing Corp., New York. 1-31.

5. Borregaard, N., J. M. Heiple, E. R. Simons, and R. A. Clark. 1983. Subcellular localization of the b-cytochrome component of the human neutrophil microbicidal oxidase. Translocation during activation. J. Cell Biol. 97:53-61.

6. Borregaard, N., and A. I. Tauber. 1984. Subcellular localization of the human neutrophil NADPH oxidase: b-cytochrome and associated flavoprotein. J. Biol. Chem. 259:47-52.
7. Todd, R. F., III, M. A. Arnaout, R. E. Rosin, C. A. Crowley, W. A. Peters, and B. M. Babior. 1984. Subcellular localization of the large subunit of Mol (Mol $\alpha$; formerly gp 110), a surface glycoprotein associated with neutrophil adhesion. J. Clin. Invest. 74:1280-1290.

8. Bainton, D. F., L. J. Miller, T. K. Kishimoto, and T. A. Springer. 1987. Leukocyte adhesion receptors are stored in peroxidase-negative granules of human neutrophils. J. Exp. Med. 166:1641-1653.

9. Yoon, P. S., L. A. Boxer, L. A. Mayo, A. Yang, and M. S. Wicha. 1987. Human neutrophil laminin receptors: activation-dependent receptor expression. J. Immunol. 138:259-265.

10. Jesaitis, A. J., J. R. Naemura, R. G. Painter, L. A. Sklar, and C. G. Cochrane. 1982. Intracellular localization of N-formyl chemotactic receptor and $\mathrm{Mg}^{2+}$ dependent ATP-ase in human granulocytes. Biochim. Biophys. Acta. 719:556-568.

11. Fletcher, M. P., and J. I. Gallin. 1983. Human neutrophils contain an intracellular pool of putative receptors for the chemoattractant N-formyl-methionyl-leucyl-phenylalanine. Blood. 62:792799.

12. Heiple, J. M., and L. Ossowski. 1986. Human neutrophil plasminogen activator is localized in specific granules and is translocated to the plasma membrane by exocytosis. J. Exp. Med. 164:826-840.

13. Lacal, P., R. Pulido, F. Sanchez-Madrid, and F. Mollinedo. 1988. Intracellular location of T 200 and Mol glycoproteins in human neutrophils. J. Biol. Chem. 263:9946-9951.

14. Gallin, J. I. 1984. Neutrophil specific granules: a fuse that ignites the inflammatory response. Clin. Res. 32:320-328.

15. Dewald, B., U. Bretz, and M. Baggiolini. 1982. Release of gelatinase from a novel secretory compartment of human neutrophils. J. Clin. Invest. 70:518-525.

16. Hibbs, M. S., A. H. Kang, and D. F. Bainton. 1986. Ultrastructural localization of human neutrophil gelatinase. Clin. Res. 34:459A. (Abstr.)

17. Miller, L. J., D. F. Bainton, N. Borregaard, and T. A. Springer. 1987. Stimulated mobilization of monocyte Mac-1 and p 150,95 adhesion proteins from an intracellular vesicular compartment to the cell surface. J. Clin. Invest. 80:535-544.

18. Berger, M., E. M. Wetzler, and R. S. Wallis. 1988. Tumor necrosis factor is the major monocyte product that increases complement receptor expression on mature neutrophils. Blood. 71:151-158.

19. Berger, M., and M. E. Medof. 1987. Increased expression of complement decay-accelerating factor of human neutrophils. J. Clin. Invest. 79:214-220.

20. Borregaard, N., L. J. Miller, and T. A. Springer. 1987. Chemoattractant-regulated mobilization of a novel intracellular compartment in human neutrophils. Science (Wash. DC). 237:1204-1206.

21. Clemmensen, I., L. C. Petersen, and C. Kluft. 1986. Purification and characterization of a novel oligomeric plasminogen kringle 4 binding protein from human plasma: tetranectin. Eur. J. Biochem. 156:327-333.

22. Christensen, L., N. Johansen, B. A. Jensen, and I. Clemmensen. 1987. Immunohistochemical localization of a novel human plasma protein, tetranectin, in human endocrine tissues. Histochemistry. 87:195-199.

23. Christensen, L., and I. Clemmensen. 1989. Tetranectin in normal human tissues: an immunohistochemical study of exocrine epithelia, and mesenchyma. Histochemistry. 92:29-35.

24. Bordier, C. 1981. Phase separation of integral membrane proteins in Triton X-114 solution. J. Biol. Chem. 256:1604-1607.

25. Gottlieb, C., K.-S. Lau, L. R. Wasserman, and V. Herbert. 1965. Rapid charcoal assay for intrinsic factor (IF), gastric juice saturated $B_{12}$ binding activity, antibody to IF, and serum unsaturated $B_{12}$ binding capacity. Blood. 25:875-893.

26. DeChatelet, L. R., and M. R. Cooper. 1970. A modified procedure for the determination of leukocyte alkaline phosphatase. Biochem. Med. 4:61-68.

27. Brittinger, G. R., R. Hirschhorn, S. D. Douglas, and G. Weissmann. 1968. Studies on lysosomes. XI. Characterization of a hydrolase-rich fraction from human lymphocytes. J. Cell Biol. 37:394-411. 
28. Bos, A., R. Wever, and D. Roos. 1978. Characterization and quantification of the peroxidase in human neutrophils. Biochim. Biophys. Acta. 525:37-44.

29. Jensen, B. A., P. McNair, L. Hyldstrup, and I. Clemmensen. 1987. Plasma tetranectin in healthy male and female individuals, measured by enzyme-linked immunosorbent assay (ELISA). J. Lab. Clin. Med. 110:612-617.

30. Burroughs, S. F., D. V. Devine, G. Browne, and M. Kaplan. 1988. The population of paroxysmal nocturnal hemoglobinuria neutrophils deficient in decay-accelerating factor are also deficient in alkaline phosphatase. Blood. 71:1086-1089.

31. Selveraj, P., W. F. Rosse, R. Silber, and T. A. Springer. 1988. The major Fc-receptor in blood has a phosphatidyl inositol anchor and is deficient in paroxysmal nocturnal hemoglobinuria. Nature (Lond.). 333:565-567.

32. Low, M. G. 1987. Biochemistry of the glycosyl-phosphatidylinositol membrane protein anchor. Biochem. J. 244:1-13.

33. Clark, R. A., and N. Borregaard. 1985. Neutrophils autoinactivate secretory products by myeloperoxidase-catalyzed oxidation. Blood. 65:375-381.

34. Bainton, D. F., J. L. Ullyot, and M. E. Farquar. 1971. The development of neutrophilic polymorphonuclear leukocytes in human bone marrow. Origin and content of specific and azurophil granules. $J$. Exp. Med. 143:907-934.
35. Spitznagel, J. K., F. G. Dalldorf, M. S. Leffell, J. D. Folds, I. R. H. Welsh, M. H. Cooney, and L. E. Martin. 1974. Character of azurophil and specific granules purified from human polymorphonuclear leukocytes. Lab. Invest. 30:774-785.

36. West, B. C., A. S. Rosenthal, N. A. Gelb, and H. R. Kimball. 1974. Separation and characterization of human neutrophil granules. Am. J. Pathol. 77:41-66.

37. Mollinedo, F., and D. L. Schneider. 1984. Subcellular localization of cytochrome $b$ and ubiquinone in a tertiary granule of resting human neutrophils and evidence for a proton pump ATP-ase. J. Biol. Chem. 259:7143-7150.

38. Parmley, R. T., W. G. Rice, J. M. Kinkade, Jr., C. Gilbert, and J. C. Barton. 1987. Peroxidase-containing microgranules in human neutrophils. Physical, morphological, cytochemical, and secretory properties. Blood. 70:1630-1638.

39. Volpe, P., K.-H. Krause, S. Hashimoto, F. Zorzayo, T. Pozzan, J. Meldolesi, and D. P. Lew. 1988. Calciosome, a cytoplasmic organelle: the inositol 1,4,5-trisphosphate-sensitive $\mathrm{Ca}^{2+}$ store of nonmuscle cells? Proc. Natl. Acad. Sci. USA. 85:1091-1095.

40. Krause, K.-H., and D. P. Lew. 1987. Subcellular distribution of $\mathrm{Ca}^{2+}$ pumping sites in human neutrophils. J. Clin. Invest. 80:107-116.

41. Smith, G. P., G. Sharp, and T. J. Peters. 1985. Isolation and characterization of alkaline phosphatase-containing granules (phosphasomes) from human polymorphonuclear leucocytes. J. Cell Sci. 76:167-178. 